\title{
A Formação Docente acerca do Pensamento Computacional na Perspectiva da Educação Inclusiva: Um Estudo sobre os Espaços de Discussão no Brasil
}

\author{
Amanda Maria D. de Oliveira, Gabriel Vieira Barreto, Flávia Roldan Viana \\ Centro de Educação - Universidade Federal do Rio Grande do Norte (UFRN) \\ Av. Sen. Salgado Filho, 3000 - Lagoa Nova, CEP: 59.078-970 - Natal - RN - Brasil \\ \{amandamaria.ufrn, flaviarviana.ufrn, gabrielvbarreto12\}@gmail.com
}

\begin{abstract}
Currently, several discussions point to Computational Thinking (CT) as a set of skills that facilitate the learning of science even for students of basic education. Therefore, it is expected that the CT will gain space in teacher training. However, it is still necessary to think about how these practices developed in the context of inclusive education, in view of the dimensions that characterize the school space as inclusive. This paper, therefore, presents a review of the literature which the results point to a deficit in studies, in Brazil, on teacher education about practices that enable the CT in the perspective of inclusive education.
\end{abstract}

Resumo. Atualmente, diversas discussões apontam o Pensamento Computacional (PC) como um conjunto de habilidades facilitadoras da aprendizagem de diversas ciências até mesmo para estudantes da educação básica. Logo, espera-se que o PC ganhe espaço nas formações para professores. Contudo, é preciso ainda pensar como essas práticas serão desenvolvidas no contexto da educação inclusiva, tendo em vista as dimensões que caracterizam o espaço escolar como inclusivo. Este trabalho apresenta, portanto, uma revisão de literatura cujos resultados apontam para um déficit em estudos, no Brasil, sobre a formação docente acerca de práticas que viabilizem o desenvolvimento do PC na perspectiva da educação inclusiva.

\section{Introdução}

Cada vez mais, no Brasil, são ampliadas discussões sobre a importância e os benefícios do aprendizado do Pensamento Computacional (PC) desde o início da Educação Básica. A Base Nacional Comum Curricular (BNCC) [Brasil 2017] aponta que, para o ensino de Matemática, devem ser pensadas e propostas atividades e experiências que promovam o desenvolvimento do PC. Isso porque, na medida em que há o desenvolvimento do PC, o aluno desenvolve habilidades para melhor "compreender, analisar, definir, modelar, resolver, comparar e automatizar problemas e suas soluções, de forma metódica e sistemática, por meio do desenvolvimento de algoritmos" [Brasil 2017, p. 9].

Contudo, para que um novo conteúdo ou abordagem metodológica seja efetivamente integrado nas salas de aula da Educação Básica é preciso que sejam implantadas políticas públicas que visem a adequação do espaço, aquisição de material e a formação docente para uso efetivo desses recursos. Além disso, é preciso que tais ações levem em consideração a promoção de uma educação inclusiva e para todos, que respeite o princípio de que: 
[...] todas as crianças devem aprender juntas, sempre que possível independente de quaisquer dificuldades ou diferenças que elas possam ter. Escolas inclusivas devem reconhecer e responder às necessidades diversas de seus alunos, acomodando ambos os estilos e ritmos de aprendizagem e assegurando uma educação de qualidade a todos através de um currículo apropriado, arranjos organizacionais, estratégias de ensino, uso de recursos e parcerias com as comunidades [...] escolas inclusivas provêem um ambiente favorável à aquisição de igualdade de oportunidades e participação total [...]. [UNESCO, 1994, p.5].

Diante disso, com o objetivo de identificar como o PC tem sido abordado, no Brasil, na formação docente diante do contexto da Educação Especial na perspectiva da Educação Inclusiva, foi realizada esta revisão de literatura nos espaços de discussão acerca da aprendizagem de computação no Brasil. Este artigo tem por objetivo responder à seguinte pergunta: Como vem sendo realizada a formação docente para o desenvolvimento do Pensamento Computacional diante do contexto da Educação Especial na perspectiva da Educação Inclusiva no Brasil?

Nas seções a seguir, são apresentados os tópicos: fundamentação teórica, que para esta pesquisa trata sobre o PC, a formação docente e a Educação Inclusiva; a metodologia aplicada, onde são descritos os passos para busca, seleção e análise dos trabalhos; os resultados e discussões, que apresentam informações extraídas dos estudos selecionados para responder à pergunta da pesquisa; e, por fim, as conclusões dos autores ao fim do estudo.

\section{Fundamentação Teórica}

Esta seção está dividida em três partes que fundamentam esta pesquisa, o PC, a Formação Docente e a Educação Inclusiva, que aqui serão brevemente conceituados.

\subsection{O Pensamento Computacional}

É só na primeira década do século XXI que surge a discussão sobre o termo "Pensamento Computacional", que eleva o termo para além da compreensão do que compete a um Cientista da Computação, mas que o reconhece como um conjunto de habilidades potencializadoras da capacidade humana de fazer ciência nas diversas áreas de conhecimento, para além da computação [Wing 2016]. É preciso ressaltar, desde já, que Ciência da Computação e Pensamento Computacional não significam e não tratam da mesma coisa, enquanto uma envolve um conjunto complexo e amplo de questões que já foram e ainda estão para ser compreendidas e respondidas por estudiosos da área [Wing 2016]; a outra reúne um conjunto de habilidades que convém a quem quer que tenha interesse em aprender e utilizá-las [Denning 2009].

“Uma forma que humanos, não computadores, pensam.” [Wing 2016, p. 4] Essa é a primeira e principal característica acerca do pensamento computacional que se deve ter clareza. Não se trata de uma forma de fazer humanos pensar como computadores, mas de um conjunto de habilidades que permitem aos humanos proporcionarem aos computadores, e máquinas no geral, realizarem atividades que a princípio só poderiam ser executadas por outros humanos [Wing 2016]. Não se trata de humanizar o computador ou computadorizar o humano, mas de sistematizar uma evolução conjunta, sendo a evolução dos computadores totalmente dependente da evolução humana e, não o contrário. Para Wing (2016), o PC trata de um conjunto de habilidades para resolução de 
problemas que todo mundo deveria saber. Contudo, o acesso ao desenvolvimento dessas habilidades ainda têm como alvo o seleto grupo que opta pelos estudos avançados em Computação em nível técnico ou de graduação, ao passo que a BNCC já traz apontamentos sobre o benefício desse aprendizado para outras ciências.

\subsection{A Formação Docente}

É papel da formação docente, seja em caráter inicial ou continuada, levar em consideração as dimensões do conteúdo, da metodologia e do papel da docência enquanto profissão. O professor precisa, antes de ensinar, conhecer o objeto de ensino e então identificar abordagens metodológicas adequadas para o ensino de tal conteúdo e, com isso, adequá-las a seus alunos de forma que todos possam ser contemplados [Franco e Lisita 2008].

A demanda pela integração do PC como ferramenta pedagógica na formação de professores se dá devido ao fato de que, os alunos são fluentes no tocante ao uso das TDIC enquanto os professores são ainda "imigrantes digitais", visto que estão se apropriando desses recursos no decorrer do exercício da profissão [Prensky 2001]. Se considerarmos o ano da publicação deste estudo de Prensky, podemos concluir que muitos dos nativos digitais frequentam hoje, ou já concluíram, cursos de graduação, nos quais a pesquisa online, a produção de texto, apresentações de slides e o uso outros recursos digitais é algo inerente às demandas de estudo independente da área de conhecimento. Tais recursos da TDIC ampliam as possibilidades de desenvolvimento do PC. Portanto, a formação docente para a integração do PC deve levar em consideração os recursos e possibilidades existentes em sala de aula, bem como se atentar para o perfil do professor. Mesmo que sejam ampliadas a oferta da formação continuada em cursos sobre ensino de computação, é preciso considerar os futuros professores que ainda estão cursando as licenciaturas e podem se beneficiar do desenvolvimento do PC para si e seus alunos, quando em serviço.

\subsection{A Educação Inclusiva}

A discussão sobre Educação Inclusiva nem sempre esteve presente nas pesquisas em Educação, uma vez que os debates sobre inclusão no Brasil ganharam força na década de 1990, com a Declaração Mundial sobre Educação para Todos [Unicef 1990] e a Declaração de Salamanca [Brasil 1994]. Desde o início da década de 1990, essas discussões passam, então, a vislumbrar a Educação Especial na perspectiva inclusiva.

Anos após os primeiros marcos da Educação Inclusiva no Brasil, esta passa a ser compreendida como aquela ofertada não mais de forma segregada da escola regular (comum), mas articulada, oferecendo recursos e serviços que garantam a plena aprendizagem do estudante público-alvo da Educação Especial (aqueles que têm impedimentos de longo prazo, de natureza física, mental, intelectual e sensorial) na classe comum, por meio do Atendimento Educacional Especializado (AEE), que subsidia a permanência do estudante com Necessidade Educacional Específica (NEE) em escola regular "com vistas à autonomia e independência [deste estudante] na escola e fora dela." [Brasil 2008].

\section{Metodologia}

Enquanto abordagem metodológica, neste estudo, foram seguidas partes das etapas da Revisão Sistemática de Literatura (RSL) definidas por Okoli (2019): definição do 
objetivo e pergunta de pesquisa; planejamento e aplicação da busca e seleção bibliográfica; extração e síntese dos dados. Contudo, partindo do entendimento que esse recorte do procedimento não caracteriza este trabalho como uma RSL mas não o descaracteriza enquanto revisão de literatura, optou-se por adotar a nomenclatura "Revisão de Literatura".

A pesquisa foi realizada entre dezembro de 2019 e janeiro de 2020 , tendo início com a definição dos principais conceitos da pesquisa para então definir a estratégia de busca. A partir da definição desses conceitos foi possível identificar os locais (onde procurar respostas para o que se deseja saber) e as strings de busca (filtro para identificar outras pesquisas que possam responder à pergunta desta pesquisa) [Okoli, 2019].

Tendo em vista que este trabalho tem por finalidade identificar como o PC tem sido abordado, no Brasil, na formação docente diante da perspectiva da Educação Inclusiva, são os principais conceitos envolvidos: Pensamento Computacional, Formação Docente e Educação Inclusiva. Com isso, foram então definidas 3 informações a serem extraídas dos trabalhos selecionados: estratégias metodológicas para desenvolvimento do PC adotadas; o perfil do professor público-alvo dessas formações; a concepção de inclusão. As fontes de busca escolhidas foram os principais eventos brasileiros que tratam, mesmo que não exclusivamente, sobre a educação em computação e, por isso, concentram estudos sobre o PC. São, esses: Anais do Congresso Sobre Tecnologias Na Educação (Ctrl+E), Anais dos Workshops do Congresso Brasileiro de Informática Na Educação (CBIE), Anais do Workshop De Informática na Escola (WIE), Anais do Workshop De Informática na Escola (WIE), Anais da Jornada de Atualização em Informática na Educação (JAIE), Anais do Workshop de Desafios da Computação Aplicada à Educação (DesafIE) e os Anais do Simpósio Brasileiro de Informática na Educação (SBIE). Foram incluídos, também, a Revista Brasileira de Informática na Educação (RBIE), os bancos nacionais de teses e dissertações (CTD Capes e BDTD) e o Portal de Periódicos da CAPES.

Com os conceitos principais e as fontes de busca definidas, foram construídas e testadas as seguintes strings de busca: "pensamento computacional" AND "formação docente" AND "educação inclusiva"; "pensamento computacional" AND ("formação docente" OR "educação inclusiva"). Essas duas primeiras strings não retornaram resultados satisfatórios quando aplicadas para qualquer parte do texto nas bases definidas. Por isso as strings foram reformuladas, resultando em: "pensamento computacional" AND (formação OR inclusão). A terceira string foi testada e apresentou entre 10 e 17 resultados em algumas das bases definidas, sendo considerado um resultado satisfatório.

As buscas foram feitas nos sistemas de busca dos próprios repositórios, com exceção apenas dos Anais do Ctrl+E que foi utilizado o buscador do Google Scholar ${ }^{1}$ aplicando a string: (formação OR inclusão) AND "pensamento computacional" source:Congresso source:sobre source:Tecnologias source:na source:Educação. Isso foi necessário devido uma limitação do repositório no qual estão hospedados os anais do evento entre 2016 e 2018.

Como critério de inclusão foi estabelecido que os trabalhos devem: 1) ser publicado a partir de 2015; 2) ter o PC para ensino ou aprendizado como cerne. Foram definidos como critério de exclusão: 1) abordar o PC como meio para aprendizado de outras ciências; 2) conceituar o PC para apresentar um recurso educativo, sem tratar da formação docente ou apresentar relação com a educação inclusiva; 3) não tratar, em qualquer aspecto, dos temas formação docente e educação inclusiva; 4) ser estudo de caráter bibliográfico.

Após a seleção dos trabalhos, aplicando os critérios de inclusão e exclusão, foi feita a leitura completa dos trabalhos selecionados com vistas a identificar uma resposta para a

\footnotetext{
${ }^{1}$ Disponível em: <https://scholar.google.com/>
} 
pergunta de pesquisa inicialmente estabelecida. Esta discussão é detalhada na seção a seguir.

\section{Resultados e Discussões}

O resultado inicial da aplicação da string nas fontes de busca resultou em 87 trabalhos ${ }^{2}$. Dentre esses, foram removidos 9 trabalhos duplicados, resultando em 78 trabalhos distintos. Após aplicação do critério de inclusão por ano da publicação, foram selecionados 72 trabalhos publicados a partir de 2015, dos quais 46 tinham como cerne o aprendizado ou desenvolvimento de habilidades do PC. Dentre essas 46 pesquisas 13 tratavam da formação docente e 2 abordavam práticas inclusivas para 0 desenvolvimento do PC. Para responder à pergunta de pesquisa, os 15 estudos foram lidos por completo e deles foram extraídas as seguintes informações: perfil do docente formado, estratégias metodológicas e concepção de inclusão (se houvesse).

Foram identificadas três diferentes perfis de professores como público-alvo das formações ofertadas, como mostra a tabela 1. No caso dos professores da Educação Básica, estão incluídos professores da Educação Infantil, professores do Ensino Fundamental, professores do Ensino Médio e aqueles que foram definidos como professores em formação inicial que atuarão na Educação Básica.

Tabela 1. Perfis de professores identificados

\begin{tabular}{lc}
\hline Perfil do professor & Qtd \\
\hline Professores da Educação Básica & \\
\hline Professores da Educação Infantil & 2 \\
\hline Professores dos Anos Iniciais Ensino Fundamental & 3 \\
\hline Professores dos Anos Finais Ensino Fundamental & 1 \\
\hline Professores do Ensino Médio & 2 \\
\hline Professores que ensinam Matemática na Educação Básica & 1 \\
\hline$\quad$ Professores da Educação Básica em Formação Inicial & 1 \\
\hline Licenciandos em Computação & 1 \\
\hline Licenciandos em Matemática & 2 \\
\hline Total & 13 \\
\hline
\end{tabular}

No que diz respeito aos professores licenciandos em Matemática, foram identificados 2 trabalhos que os colocam como público-alvo. Em um trabalho, os licenciandos em Matemática aparecem juntamente aos professores que ensinam matemática já atuantes na Educação Básica, e outro que trata especificamente de professores de matemática em formação inicial.

Quanto à abordagem metodológica para desenvolvimento do PC, foi observado a aplicação de métodos mistos que envolvem o uso do computador e atividades desplugadas, aquelas que exploram o espaço e a interação entre os envolvidos sem o uso do computador [Bell, et al 2011]. Como mostra a tabela 2, quando feito o uso do computador, foram priorizadas atividades de programação, utilizando blocos de programar ou uma linguagem de programação específica.

\section{Tabela 2. Abordagens metodológicas para o desenvolvimento} do PC identificadas

\footnotetext{
${ }^{2}$ Listagem completa dos artigos identificados disponível em <http://gg.gg/ko5ov>.
} 


\begin{tabular}{lc}
\hline Abordagem metodológica para desenvolvimento do PC & Qtd \\
\hline Uso do computador & \\
\hline Softwares de pacote de escritório & 2 \\
\hline Softwares de edição de vídeo & 2 \\
\hline Jogo de programar LightBot & 3 \\
\hline Robótica educacional com LEGO & 2 \\
\hline Programação em blocos & 8 \\
\hline Programação em Python & 1 \\
\hline Computação desplugada & 7 \\
\hline Total & 25 \\
\hline
\end{tabular}

Nos dois trabalhos que tratam da perspectiva inclusiva para desenvolvimento do PC é possível identificar que concepção de inclusão adotada pelos autores converge para o que é previsto na definição de Educação Inclusiva de estudantes com NEE. Isso porque buscam adequar as atividades planejadas para que todos os alunos envolvidos possam participar sem distinção e tenham acesso ao mesmo conteúdo. Contudo, em outros trabalhos dentre os selecionados, o termo inclusão estava associado à promoção da inclusão digital por meio do PC ou inclusão do PC como conteúdo na Educação Básica, não fazendo qualquer alusão à Educação Inclusiva.

A seguir, são apresentados breves resumos dos trabalhos analisados com vistas a evidenciar os fatos apontados nas tabelas 1 e 2. Para isso, foram definidas duas subseções que destacam, respectivamente, o PC na formação docente e as abordagens metodológicas; e o PC na perspectiva da educação inclusiva e as abordagens metodológicas.

\subsection{Pensamento Computacional: Formação de Professores e Abordagens Metodológicas}

A pesquisa realizada por Torcate, de Farias, da Silva e Martins (2018), teve como participantes alunos em estágio supervisionado do curso de Licenciatura em Computação. Estes estudantes planejaram e ministraram aulas para uma turma do $6^{\circ}$ ano do Ensino Fundamental, na disciplina de Computacional Educacional. Como abordagem metodológica, foram desenvolvidas atividades desplugadas escolhidas baseadas no material Computer Science Unplugged [Bell et al 2011] e, também, atividades plugadas, realizadas no laboratório de informática da escola, utilizando o Code.Org, Blockly Games e Lightbot. Foi observado pelos pesquisadores que o espaço da sala de aula é fundamental para a aprendizagem dos licenciandos enquanto professores em formação mesmo que, no caso da Computação, ainda não existam políticas que reforcem a importância desses profissionais em escolas da Educação Básica [Torcate et al 2018]. Silva, Souza e Morais (2016) apresentam a adoção de abordagens semelhantes em um relato de experiência de estudantes da Licenciatura em Computação na disciplina de estágio.

Em Barbosa (2019), foi realizado um trabalho com estudantes do curso de Licenciatura em Matemática, na disciplina de Informática e Educação Matemática. Esse estudo teve como base os apontamentos da BNCC para as contribuições do PC para o aprendizado da Matemática na Educação Básica e, para fomentar tal discussão com os alunos, foram realizadas atividades de programação em blocos com o Scratch. Foi observado, contudo, que os professores em formação inicial tendiam a propor atividades didáticas com foco no uso do recurso tecnológico, sem se atentar para $o$ desenvolvimento das habilidades e utilizavam-se de métodos tradicionais com foco no ensino [Barbosa 2019]. Barcelos e colaboradores (2016) apresentam uma formação 
online para professores que ensinam matemática na Educação Básica e estudantes da licenciatura em Matemática também utilizando a programação em blocos com a ferramenta Scratch.

O público-alvo docente da pesquisa de Costa e colaboradores (2019) foram professores com diferentes perfis de formação inicial que estavam cursando mestrado. A proposta foi aplicada na disciplina de Tópicos de Informática no Ensino e teve como abordagem o desenvolvimento de aplicativos com programação em blocos utilizando MIT App Inventor. Ao final, com a avaliação dos aplicativos desenvolvidos, foi observado que as habilidades do PC foram mobilizadas para o desenvolvimento do produto educacional, assim como na busca por estratégias pedagógicas diferenciadas para a aprendizagem [Costa et al 2019]. Já Santos do Carmo Paz (2017) apresenta em seu estudo, também realizado com professores da Educação Básica em exercício, um curso de formação com duração de quatro meses intitulado "Introdução as TICs para professores" que faz uso de recursos de escritório. Santos e colaboradores (2016) realizaram uma oficina de curta duração sobre PC para professores da Educação Infantil, público que atua na Educação Básica com crianças de 0 a 5 anos. Para apresentação dos conceitos introdutórios foi utilizado curso iniciante disponível na plataforma Code.Org. As mesma atividade, envolvendo sequência de comandos e detecção de erros, foram propostas em formato desplugado, contudo o nível das atividades foi condizente ao nível do público da Educação Infantil. Ao final, os professores consideraram as atividades aplicáveis com ajustes, bem como foram coletados relatos de professores que informaram aplicar em sala de aula atividades que envolvem habilidades do PC [Santos et al 2016]. No trabalho de Bremm (2018), também direcionado a professores da Educação infantil, foram realizadas atividades desplugadas, como o desenho de fatos em sequência, e atividades plugadas com o software ScratchJr [Bremm 2018].

Souza, Rodrigues e Andrade (2016) apresentam um curso de formação realizado com professores de química, física e professores de disciplinas específicas do Ensino Médio integrado ao nível técnico. Como recurso didático-metodológico foi utilizado o kit LEGO®, composto por componentes eletrônicos e fascículos para professores, alunos e manual de montagem. Os pesquisadores apontam que esse material é utilizado pelos professores em oficinas de robótica que são realizadas com os alunos em suas respectivas disciplinas. Foi observado que, no decorrer do curso, os professores desenvolveram autonomia para programar os robôs do kit e demonstraram compreender os pilares do PC [Souza, Rodrigues e Andrade 2016].

Em Martinelli (2019) é realizada uma formação com professores dos Anos Iniciais do Ensino Fundamental, na qual foram apresentadas abordagens plugadas e desplugadas para o desenvolvimento do PC relacionado a conteúdos regulares. São apresentados indícios de que abordar o tema $\mathrm{PC}$ em consonância com documentos oficiais, como a BNCC, pode facilitar a apropriação por parte dos professores, implicando em um melhor entendimento para aplicação em sala de aula [Martinelli 2019]. Já para Gonçalves, Portella e Luz (2019), o PC é desenvolvido em paralelo à aprendizagem de uso das TDIC na medida em que os professores são apresentados a situações problema para lidar com esses recursos para fins diversos.

\subsection{O Pensamento Computacional: Educação Inclusiva $\mathrm{e}$ Abordagens Metodológicas}


A pesquisa de Lopes e colaboradores (2019) consiste em aulas de Robótica realizadas em uma Associação de Pais e Amigos dos Excepcionais (APAE) que atende à pessoas com deficiência intelectual. Foi utilizada a metodologia de Robótica Educacional com o kit Lego Boost ${ }^{\circledR}$ aliado à atividades de computação desplugada. O kit é composto por componentes eletrônicos diversos, manuais para construção de cinco diferentes robôs e sua programação é feita em blocos. As atividades foram planejadas e revisadas por um especialista para verificar a adequação ao público-alvo. Foi evidenciado que, para além das habilidades do PC, houve um ganho na interação social entre os estudantes no decorrer das aulas de Robótica [Lopes et al 2019].

Em Silva, Santos e Orleans (2019) é apresentada a oferta de aulas de Computação para estudantes com e sem NEE. Para tanto, as aulas foram planejadas na abordagem do Desenho Universal para Aprendizagem, com vistas a atender, sem distinção, estudantes com e sem NEE. Foram utilizadas atividades de computação desplugada, programação em blocos com Scratch e programação Python. Foi observado que os alunos evoluíram em termos de concentração e capacidade de abstração no decorrer das aulas [Silva, Santos e Orleans 2019].

A seguir, com as conclusões retiradas deste estudo, é apresentada também a resposta inferida para a pergunta inicialmente estabelecida, com base nos resultados e discussões apresentados neste tópico.

\section{Conclusões}

Este trabalho apresenta uma revisão de literatura em espaços de discussão no Brasil sobre a aprendizagem de computação. São identificados 13 artigos que contemplam a formação docente para o ensino e aprendizagem do PC e 2 que contemplam a proposta de práticas inclusivas para o desenvolvimento do PC. Em nenhum dos trabalhos nos quais foram identificadas experiências de formação docente houve a menção sobre a presença de professores que atuam na educação especial ou que tenham estudantes com NEE.

Diante do exposto, em resposta à pergunta de pesquisa "Como vem sendo realizada a formação docente para o desenvolvimento do Pensamento Computacional diante da perspectiva da educação inclusiva no Brasil?", conclui-se que, nos estudos analisados, essa formações têm como público-alvo principal os professores da Educação Básica e são aplicadas abordagens metodológicas que envolvem o uso ou não das TDIC. Essas abordagens demonstram auxiliar o desenvolvimento do PC na formação docente e na perspectiva da Educação Inclusiva. Contudo, é evidenciado que, nos espaços de discussão analisados, as discussões da formação docente para o desenvolvimento do PC ainda não incluem discussões que fomentem a promoção de uma educação inclusiva.

O PC, como um conjunto de habilidades que todos deveriam aprender, portanto, não deve haver distinção acerca do público ao qual se destina o desenvolvimento dessas habilidades. Dessa forma, é preciso que professores que atuam no AEE sejam incluídos nestes espaços de formação e licenciandos em computação sejam formados para atuar em uma sala de aula inclusiva. Para tanto, é imprescindível que sejam pensadas práticas inclusivas desde a formação inicial docente para o trabalho com o PC e que os espaços de discussão sobre pesquisas acerca do PC abram esse debate. 
Como trabalho futuro, e já em andamento, tem-se por propósito propor e analisar os resultados de um curso de formação voltado para professores do AEE, que demonstre práticas pedagógicas inclusivas que viabilizem o desenvolvimento do PC.

\section{Referências}

(1994) "Declaração de Salamanca". Sobre Princípios, Políticas e Práticas na Área das Necessidades Educativas Especiais. Brasília, DF.

(2008) "Política nacional de educação especial na perspectiva da educação inclusiva". Brasília, DF: Secretaria de Educação Especial, Ministério da Educação, 2008 .

Barbosa, L. (2019) “A inserção do Pensamento Computacional na Base Nacional Comum Curricular: reflexões acerca das implicações para a formação inicial dos professores de matemática". In: Anais do Workshop de Informática na Escola. p. 889-899.

Barcelos, T., Bortoletto, R., Andrioli, M. (2016) "Formação online para o desenvolvimento do Pensamento Computacional em professores de Matemática". In Anais dos Workshops do Congresso Brasileiro de Informática na Educação, vol.5, n.1, 1228-1238.

Bell, T., Witten, I., Fellows, Mike. (2015) "CS Unplugged: an enrichment and extension programme for primary-aged students". Disponível em $<$ https://classic.csunplugged.org/wp-content/uploads/2015/03/CSUnplugged_OS_20 15_v3.1.pdf>. Acesso em: jul. 2020.

Brasil. Ministério da Educação. Secretaria da Educação Básica. (2017) "Base nacional comum curricular. Brasília, DF. Disponível em: <http://basenacionalcomum.mec.gov.br/\#/site/inicio>. Acesso em: jul. 2020.

Bremm, C. I. (2018) "Mediação do pensamento computacional e programação no processo de interação das crianças na educação infantil". Dissertação de Mestrado, Universidade Federal de Santa Maria, Santa Maria, RS, Brasil.

Costa, R. D. A., Webber, C. G., Affeldt, B. B., Werle, C., Nunes, J., \& dos Reis, K. R. (2019) "Desenvolvimento e avaliação de aplicativos para dispositivos móveis por professores da Educação Básica”. Scientia cum Industria, 7(1), 27-32.

Denning, P. J. (2009) "The profession of IT Beyond computational thinking". Communications of the ACM, 52(6).

Franco, M. A. S. e Lisita, V. M. S. D. S. (2008) "Pesquisa-ação: limites e possibilidades na formação docente". In: Pesquisa em educação: possibilidades investigativas/formativas da pesquisa-ação. São Paulo: Loyola, 2, 41-70.

Gonçalves, L. M., Portella, A. C. F., Luz, M. D. S. L. (2019). "Softwares Livres e Equipamentos Manufaturados: possíveis recursos para a integração curricular das TDIC". Revista Observatório, v5, n.1, 455-477.

Lopes, J. C. D. C., Queirós, D. D. S., Santos, H. D., Souza, E., Albuquerque, H. O., Albuquerque, H. J. O. (2019) "Ensino de Robótica para a Promoção da Inclusão Sociodigital de Pessoas com Deficiência: um Relato de Experiência". In Anais do IV Congresso sobre Tecnologias na Educação, 98-107. 
Martinelli, S. R. (2019) "MultiTACT: Uma abordagem para a construção de atividades de ensino multidisciplinares para estimular o Pensamento Computacional no Ensino Fundamental I". Dissertação de Mestrado, Universidade Federal de São Carlos, Sorocaba, SP, Brasil.

Matos, E., Coutinho, C. B., Santos, E., Dourado, H. M., Ribeiro, L., da Silva, R. S., ... \& de Morais, P. S. (2019) "Desafios da Tutoria em um Curso Online de Formação de Professores para Desenvolvimento do Raciocínio Computacional". In Anais do IV Congresso sobre Tecnologias na Educação, 251-259.

Okoli, C. (2019). “Guia para realizar uma Revisão Sistemática de Literatura”. EAD em Foco, 9(1).

Prensky, M. (2012) “Aprendizagem baseada em jogos digitais”. São Paulo: Editora Senac São Paulo.

Santos, E. R., Soares, G., Dal Bianco, G., da Rocha Filho, J. B., \& Lahm, R. A. (2016) "Estímulo ao Pensamento Computacional a partir da Computação Desplugada: uma proposta para Educação Infantil”. Revista Latinoamericana de Tecnología Educativa, 99-112.

Santos do Carmo Paz, L. A. (2017) "Computational Thinking And Teachers Continuing Education: An Experience With ICTS". Revista On Line De Politica E Gestao Educacional, 21, 1655-1265.

Silva, N., Santos, I., Orleans, L. (2019) "Ensino Inclusivo de Pensamento Computacional: um Relato de Experiência”. In Anais do XXVII Workshop sobre Educação em Computação, 81-90.

Silva, V., da Silva, L. L., França, R. (2017) "Pensamento computacional na formação de professores: experiências e desafios encontrados no ensino da computação em escolas públicas". In Anais do Workshop de Informática na Escola, v.23, n.1, 805-815.

Silva, V., Souza, A., Morais, D. (2016) "Pensamento computacional no ensino de computação em escolas: Um relato de experiência de estágio em licenciatura em computação em escolas públicas". In Congresso Regional Sobre Tecnologias na Educação, 324-325.

Souza, I. M. L., Rodrigues, R. S., Andrade, W. (2016) "Introdução do pensamento computacional na formação docente para ensino de robótica educacional". In Anais dos Workshops do Congresso Brasileiro de Informática na Educação, vol.5, n.1, 1265-1275.

Torcate, A. S., de Farias, M. U. F., da Silva, S. R. F., \& Martins, C. S. (2018) "A inserção de Computação como disciplina no Ensino Fundamental: Desafios e Conquistas em Estágio Supervisionado". In Anais do XXVI Workshop sobre Educação em Computação, sem paginação.

UNICEF. (1990) "Declaração Mundial sobre Educação para todos." Satisfação das Necessidades Básicas de Aprendizagem. Jomtiem.

Wing, J. (2016) "Pensamento Computacional - Um conjunto de atitudes e habilidades que todos, não só cientistas da computação, ficaram ansiosos para aprender e usar". Revista Brasileira de Ensino de Ciência e Tecnologia, v. 9, n. 2. 